\title{
DESIGN E EMOÇÃO: uma análise da relação entre usuários e artefatos de design desenvolvidos e lançados no mercado consumidor brasileiro entre os anos de 1990 e 2010
}

\author{
Washington Ferreira Silva \\ Universidade Federal da Paraíba - UFPB \\ washington.ufpb@gmail.com \\ Virginia Pereira Cavalcanti \\ Universidade Federal de Pernambuco - UFPE \\ cavalcanti.virginia@gmail.com
}

Resumo: Este artigo trata da relação entre o design emocional e o processo de desenvolvimento projetual contemporâneo, tendo como objetivo analisar artefatos de design desenvolvidos e lançados no mercado consumidor brasileiro entre os anos de 1990 e 2010 e sua relação entre os aspectos emocionais oriundos dos estímulos sensoriais. Para tanto, se desenvolveu um estudo exploratório sobre o cenário do design, do usuário e da emoção, identificando a construção dos significados através da relação estabelecida entre eles. Na pesquisa, foram escolhidos artefatos de design que tiveram destaque em revistas da área cuja análise foi realizada sob uma perspectiva emocional, utilizando o MADE, Modelo de Análise do Design Emocional, construído durante o processo deste trabalho, sugerindo uma nova proposta de classificação. Os resultados sinalizaram, através da pesquisa e análise desenvolvida, que é possível evidenciar e analisar a relação existente no desenvolvimento de artefatos de design e os aspectos emocionais despertados nos usuários através da sua relação com estes objetos, mesmo que inicialmente seja difíceis prever qual o tipo e o grau de envolvimento que estes possam estabelecer.

Palavras-chave: design, emoção, metodologia

Abstract: This research studies the relationship between emotional design
and development process projectual, aiming at analyzing design artifacts
developed and sold in the Brazilian consumer market between 1990 and
2010 and their relationship between the emotional aspects. Therefore
developed an exploratory study on the stage of design, user and emotion,
identifying the construction of meaning through the relationship
established between them. In the survey, were chosen design artifacts that
have featured in magazines in the area whose analysis was carried out
under an emotional perspective, using MADE, Analysis Model of Design and 
Emotion, built during this study, suggesting a new classification proposal. The results indicate, through research and analysis developed, it is possible to observe and analyze the relationship in the development of design artifacts and the emotional aspects aroused in the users through their relationship with these objects, even if initially it is difficult to predict what type and the degree of involvement that they can establish.

Keywords: design, emotion, methodology

\section{INTRODUÇÃO}

Nos dicionários da língua portuguesa encontramos mais de 300 definições para a palavra emoção, das quais cerca de 20 estão associadas a produtos. Alguns desses conceitos estão associados com sensação e percepção (captação e tratamento inicial do estimulo, nível fisiológico), cognição (atribuição de significado e associações, conhecimento, memória, experiências anteriores), afeto (nível fisiológico, nível reduzido de consciência), emoção (nível maior de processamento da informação, atribuição de significado, identificação do objeto causador) e sentimento (atribuição de valores, prédisposição de comportamento, mais estável e duradouro) (ITIRO IIDA,2007).

Outra associação relacionada aos produtos foi apresentada em meados das décadas de 60 e 70 por Löbach (2001). Ele classifica as funções de um produto como prática, estética e simbólica, as quais constituem os aspectos essenciais das relações entre os usuários e seus produtos. Esse princípio das funções (Prática, Estética e Simbólica) de Löbach (2001) é interpretado na área do design emocional com outra classificação exposta por Norman (2008) envolvendo os três aspectos do design: visceral, comportamental e reflexivo.

Estas três dimensões fazem parte do design de qualquer produto e estão interrelacionadas entre si. Estes componentes relacionam-se quer com as emoções, quer com a cognição ou razão. Para Damásio (2006), a cognição e/ou a razão ajudam a interpretar e compreender o mundo, enquanto a emoção permite que tomemos decisões mais rápidas sobre este.

Quando escolhemos um produto, não pensamos só na sua usabilidade. O componente estético também tem uma interferência muito relevante nesse processo de seleção. Desta forma, a opção por um produto em detrimento de outro tem também um caráter mais psicológico, relacionado com as emoções (DAMÁsIO, 2006).

Em entrevista a Revista Veja, Damásio (2001) afirma que as emoções são extraordinariamente importantes no processo de decisão, elas fazem parte do mecanismo neurológico da decisão. Isto é, a escolha de um produto depende da ocasião, do contexto e, principalmente, do estado de espírito onde, em muitos casos, as emoções suplantam os aspectos racionais. A explicação para esse fenômeno é simples: quando nos deparamos com algo que julgamos atraente, isso nos causa uma sensação de bem-estar. Isto também é cientificamente comprovado, como pode ser observado a seguir:

pessoas com deficiências cerebrais que afectam o sistema emocional têm dificuldades em escolher entre duas alternativas, especialmente se estas forem muito semelhantes entre si ou equivalentes (DAMASIO, 2006).

De acordo com o autor, quando uma pessoa se sente bem consegue, mais facilmente, encontrar soluções mais criativas para os problemas. E é nesta fase que 
entra o componente estético. Produtos mais atrativos esteticamente fazem com que os seus usuários sintam-se melhor, fazendo com que eles pensem de uma forma mais criativa. Ponto de vista corroborado por Norman (2008) que afirma:

A emoção positiva de um belo objeto é imediatamente lida por nosso cérebro como vinda de uma coisa boa, funcional. "É por isso que escolhemos sempre aquilo que nos parece mais bonito, e não coisas que são apenas uma utilidade pura e simples. Até porque as coisas bonitas, por causarem uma boa sensação, também nos dão a impressão de funcionarem melhor".

Diante disso, o designer deve considerar o estado psicológico do seu públicoalvo e não priorizar apenas a função prática do produto. $O$ pensamento racional rejeita as soluções advindas da intuição e da emoção, considerando-as como elaborações de segunda ordem. Contudo, desenvolvimentos recentes em design colocam a emoção e o prazer como foco de uma nova metodologia, tirando-os da marginalidade a que estavam relegados.

Os objetos representam muito mais do que sua própria materialidade e funcionalidade, pois sua existência tem relação com a vida dos indivíduos consumidores. Através das relações sociais nas quais estão envolvidos, os produtos conquistam significados que podem estar relacionados aos aspectos funcionais do produto, mas principalmente aos valores simbólicos a ele atribuídos (FAGGIANI, 2006).

Já existem muitos conhecimentos acumulados e metodologias estabelecidas para se resolver os aspectos racionais do produto. Contudo, ainda pouco se conhece sobre as emoções exercidas pelos produtos. O profissional de design deve equilibrar adequadamente esses dois conjuntos de fatores, pois como afirma Norman (2008), quem comanda as nossas escolhas são as emoções. Para este autor, "quem entra em ação nessa hora é o sistema afetivo - o responsável em nosso organismo por julgar o que é bom ou ruim, seguro ou perigoso. Nada a ver com a razão ou com a lógica". Desta forma,

os objetos são uma forma de interagirmos com os outros. Eles servem para que sejamos aceitos socialmente, para nos tornar mais adequados à sociedade em que vivemos. Quando você compra um sofá, certamente pensa também nos seus amigos que vão se sentar nele (DAMAZIO, 2008).

Neste contexto, os objetos adquirem significado porque estão o tempo todo ali, testemunhando passagens da nossa vida. "Quanto mais velhos ficamos, menos neutros ficam os objetos à nossa volta. A gente mede a maturidade de uma pessoa a partir da história das suas coisas", disse a autora (op.cit).

Assim na prática da metodologia do design não devemos priorizar apenas os aspectos funcionais do produto em detrimento dos aspectos culturais e emocionais, uma vez que está cientificamente provado que estes últimos aspectos detém um poder de influência maior no processo de aquisição de produtos, sendo cada vez mais valorizados pela sociedade atual. Logo, este trabalho visa entender melhor a relação dos artefatos de design e sua relação com os aspectos emocionais. Dessa forma, a pergunta que norteou o desenvolvimento deste trabalho foi: de que forma pode-se evidenciar a relação entre o design e os aspectos emocionais oriundos dos estímulos sensoriais nos artefatos desenvolvidos e lançados no mercado consumidor brasileiro entre os anos de 1990 e 2010 ?

\section{ESTRUTURAÇÃO DA PESQUISA}

A pesquisa foi desenvolvida em duas partes principais, a primeira composta pela fundamentação teórica e a segunda pelo desenvolvimento da pesquisa. Cada uma destas partes inclui procedimentos e métodos específicos de acordo com os objetivos deste trabalho, como podemos visualizar na imagem seguinte: 


\begin{tabular}{lll}
\hline & Fases da Pesquisa & \multicolumn{1}{c}{ Objetivos } \\
\hline Parte I & Pesquisa Bibliográfica & $\begin{array}{l}\text { Levantamento das bases teóricas sobre design emocional, } \\
\text { através de uma revisão bibliográfica que contempla o } \\
\text { design, emoção e usuários. }\end{array}$ \\
\hline \multirow{2}{*}{ Parte II } & $\begin{array}{l}\text { Análise das metodologias } \\
\text { existentes }\end{array}$ & $\begin{array}{l}\text { Verificação das metodologias projetuais de design e as } \\
\text { principais técnicas que envolvemo design emocional; } \\
\text { Elaboração de um modelo de análise do tipo de } \\
\text { envolvimento entre produto e usuário baseado na revisão } \\
\text { bibliográfica e nas ferramentas de metodologia. }\end{array}$ \\
\cline { 2 - 3 } & Coleta de dados & $\begin{array}{l}\text { Mapear artefatos de design que tiveram destaque em } \\
\text { revistas da área sob uma perspectiva emocional. }\end{array}$ \\
\hline
\end{tabular}

Figura 1 - Estruturação da pesquisa.

Fonte: Elaborado pelo autor, com base na pesquisa realizada.

\subsection{Pesquisas Bibliográficas}

O delineamento estratégico desta pesquisa teve início com a pesquisa bibliográfica sobre o tema, através da qual foi possível aprofundar os conhecimentos sobre design, emoção e usuários. Estas informações nortearam desde a escolha dos métodos utilizados, passando pela elaboração dos instrumentos de coleta até à análise dos dados, tudo em consonância com os objetivos propostos.

Para a realização desta etapa, os materiais bibliográficos foram levantados através da consulta de livros, dissertações e periódicos científicos especializados, como também se utilizou a Internet como ferramenta de busca de informações relevantes neste estudo. $O$ estudo do design e emoção, por se tratar de um tema que só recentemente vem sendo pesquisado, esta pesquisa compartilhou conceitos e teorias similares que envolvem os fatores emocionais e sua interação com o usuário.

A partir das teorias levantadas e estudadas durante esta etapa, foi possível coletar subsídios para a elaboração de um modelo de análise no capítulo seguinte.

\subsection{Análises das metodologias existentes}

Nesta fase, os dados coletados para a análise das metodologias também foram extraídos de livros, dissertações, periódicos e Internet. Todavia, utilizou-se o método de Mapas de Associações de Ideias para a realização das análises e a elaboração de um modelo de análise do design emocional.

Essa técnica, segundo Vergara (2008), tem como objetivo subsidiar o processo de análise e interpretação dos dados da pesquisa a fim de facilitar a comunicação de seus resultados. Sua construção confere visibilidade ao processo de análise por meio da organização de dados em colunas que correspondam a categorias temáticas definidas pelo pesquisador.

Por ser um método flexível, adapta-se tanto a organização dos dados, contribuindo para sua interpretação, quanto à apresentação da análise, permitindo ao leitor compreender melhor a trajetória percorrida no tratamento dos dados. Como resultado desta ferramenta, foram gerados neste capítulo mapas com as associações das ferramentas e métodos de design.

Por outro lado, esta ferramenta proporcionou a criação de um novo Modelo de Análise do Design Emocional, o MADE. A construção desta ferramenta só foi possível graças ao cruzamento dos dados obtidos na fundamentação teórica com as análises das ferramentas e modelos já existentes que envolvem o design e a emoção. 


\subsection{Coletas de Dados}

Esta fase foi divida em três etapas. Na Etapa 1 - Seleção dos objetos de estudo - foram selecionados os objetos de estudo da pesquisa. Para tanto, foram analisadas três revistas especializadas em design, conforme apresentação a seguir:

A revista ABCDesign foi lançada no mercado em 2001, com a proposta de se criar um meio de informação que abordasse a história e os valores do design, bem como refletir sobre a prática, a teoria e sua importância cultural para a sociedade. Sua periodicidade é trimestral e possui abrangência nacional. Para esta pesquisa, foram analisadas as edições de números 18 à 35 .

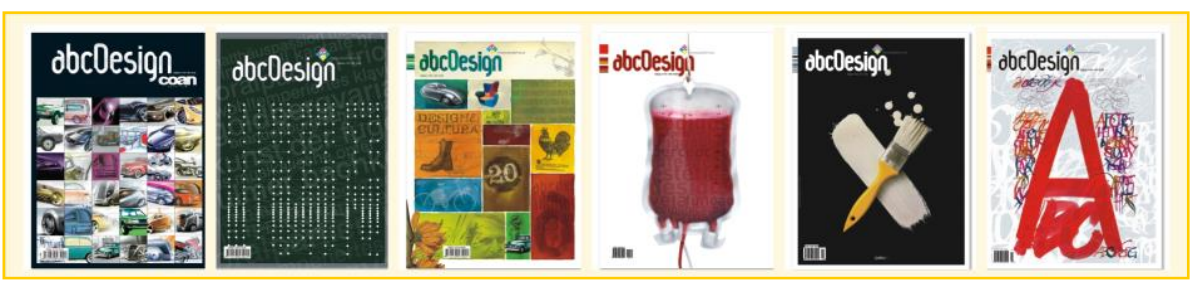

Figura 2 - Revistas ABCDesign.

Fonte: Elaborado pelo autor, com base na pesquisa realizada.

A revista ARC Design foi lançada em julho de 1997, sendo hoje a principal publicação nacional dedicada ao design. É voltada principalmente à divulgação e crítica do design nacional e internacional em seus mais diversos segmentos. Foram analisadas as edições de números 40 à 73 deste periódico.
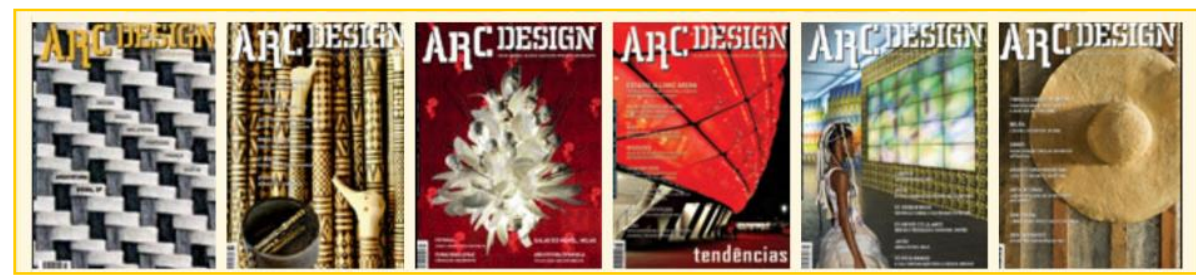

Figura 3 - Revistas ARC Design.

Fonte: Elaborado pelo autor, com base na pesquisa realizada.

A revista Voxel é uma publicação da Editora Zupi, lançada no mercado em 2009, é inteiramente focada em Design de Produtos, Design de interiores, Arquitetura e 3D. A publicação possui formato de livro de arte e tem como proposta apresentar projetos e portfólios de renomados profissionais a partir de novas tendências e projetos originais. Foram analisadas as edições de $n=00$ a 04.

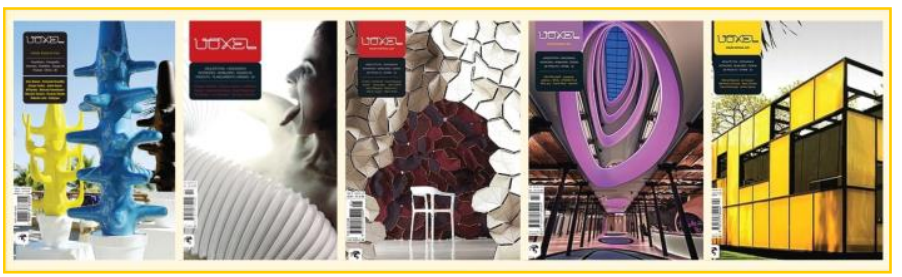

Figura 4 - Revistas VOXEL.

Fonte: Elaborado pelo autor, com base na pesquisa realizada.

Após a realização das análises das revistas referidas, foram selecionados cinco objetos de estudo conforme os seguintes critérios estabelecidos: Produtos destinados para a população de massa (fácil aquisição, preço baixo); Que tiveram destaque em revistas da área (ABC Design; ARC Design e Voxel) entre os anos de 2000 e 2011; 
Desenvolvidos e lançados no mercado consumidor brasileiro neste período; Assinados por estudantes, profissionais ou profissionais em design brasileiros; Receberam prêmios e destaque em empresas da indústria nacional.

Realizada a busca por objetos que cumprissem os critérios supracitados, foram selecionados cinco produtos que mais se enquadravam aos requisitos proposto:

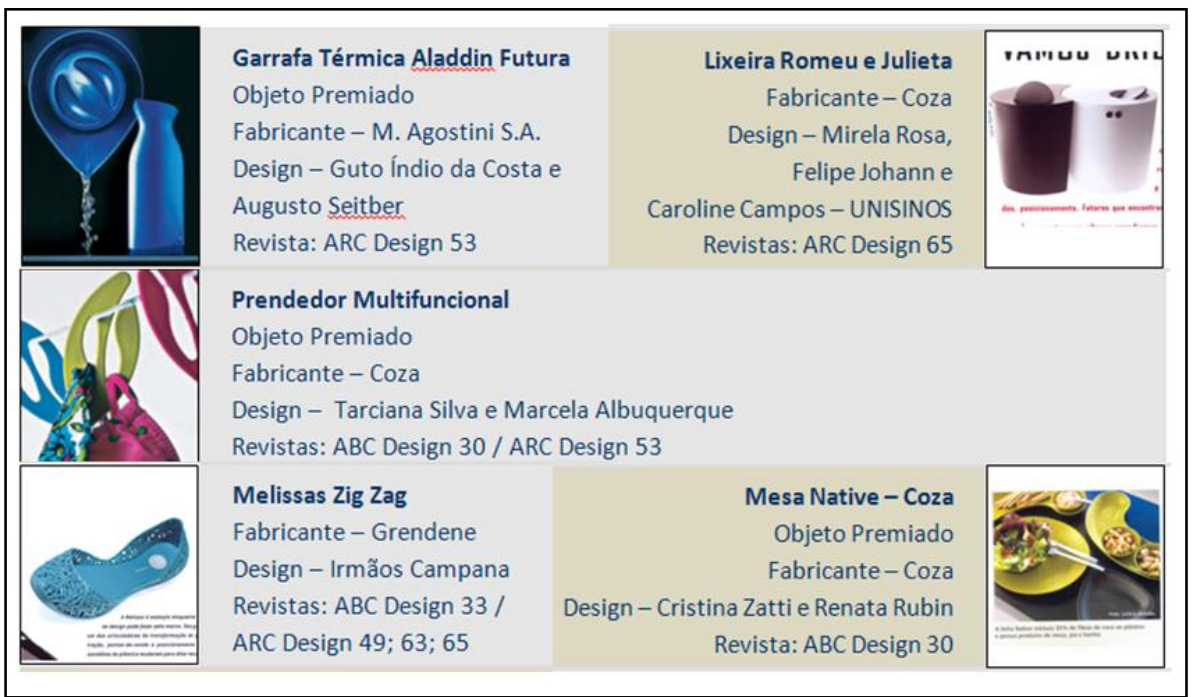

Figura 5 - Objetos selecionados para o desenvolvimento da pesquisa.

Fonte: Elaborado pelo autor, com base na pesquisa realizada.

Após a apresentação dos produtos, foi realizada a técnica de focus group Etapa 2 - envolvendo especialistas para a análise dos produtos selecionados. 0 objetivo desta etapa foi identificar como os profissionais envolvidos com o desenvolvimento de produtos analisam o design dos objetos à luz dos sistemas sensoriais, levando-se em consideração as impressões causadas por esses, além de tentar identificar em qual nível do MADE o objeto estaria inserido.

O Focus Group é um método de coleta de dados que consiste na realização de entrevistas em um grupo, conduzidas por um moderador, tendo-se como objetivo da discussão um tópico específico (VERGARA, 2008). Trata-se de uma técnica com abordagem mais qualitativa, sendo mais exploratória e menos estruturada que outros procedimentos metodológicos. Este procedimento é recomendável quando se faz necessário avaliar novos conhecimentos e novas ideas. Além do mais, o pesquisador ao se utilizar desta técnica pode avaliar as percepções, os sentimentos, as atitudes e as motivações dos entrevistados, uma vez que este método permite a observação e os comentários subjetivos dos indivíduos participantes.

Seguindo as instruções de Vergara (2008), com a definição do tema e do objeto da pesquisa, iniciou-se o planejamento para a realização do focus group, em que os participantes foram convidados por e-mail e telefonemas, uma semana antes da realização do evento. Além disso, foi construído um roteiro como forma de direcionamento da pesquisa.

De acordo com Morgan (1997 apud VERGARA, 2008), recomenda-se entre seis e dez participantes para a realização de uma sessão de focus group, além de um moderador e assistente, caso haja necessidade. Desta forma, para a realização do focus group com os especialistas foram convidados sete participantes especialistas que, em conjunto com o moderador e um assistente, compuseram a equipe para este procedimento. 
Durante o focus group, o moderador apresentou o objetivo do estudo, demonstrou os produtos a serem analisados e orientou a discussão através de um roteiro de estrutura aberta e flexível. O assistente anotou as impressões dos participantes provenientes das discussões ocorridas durante o evento. Os dados foram coletados e serviram de base para análise dos produtos em estudo.

Já na Etapa 3 - entrevistas com usuários - O objetivo foi confrontar os dados levantados pelos especialistas com as respostas dos usuários destes objetos, além de identificar através do MADE o nível de envolvimento entre usuários e objetos. Desta forma, foi elaborado um questionário cujas respostas foram obtidas a partir redes sociais da Internet (meios eletrônicos assíncronos).

A estrutura deste questionário seguiu as recomendações propostas por Roesch (2007), com perguntas abertas, constituindo uma forma de coletar dados qualitativos. O propósito de formular tais questões é permitir ao pesquisador entender e capturar a perspectiva dos respondentes. Além disso, o uso desse tipo de perguntas, permite ao pesquisador obter outros dados, pois a citação direta (resposta do sujeito pesquisado) apresenta a forma como o respondente organiza suas ideias e pensamentos sobre o que está acontecendo, suas expectativas e percepções básicas.

\subsection{Análises dos resultados}

Na pesquisa qualitativa, segundo Merriam (1998) a análise de dados é feita, concomitante à coleta, de forma a identificar algum aspecto que precise ser reelaborado, enquanto o pesquisador ainda estiver no campo. Esta etapa consistiu em comparar continuamente os incidentes, ou seja, o conteúdo de dados que emergiram da coleta. Desta forma, a análise foi iniciada a partir das informações recebidas pelo pesquisador, comparando-as no conjunto de dados. Em seguida, os dados coletados e as análises parciais foram interpretados conjuntamente, visando formar um todo coerente e detalhado sobre o fenômeno.

Por outro lado, o tratamento das informações coletadas foi respaldado na análise do conteúdo, através da organização do focus group e das entrevistas, buscando-se o significado nuclear das respostas individuais e, posteriormente, sua análise e categorização em conjunto, contemplando as opiniões de todos os entrevistados.

\section{DESENVOLVIMENTO}

Com relação aos objetivos propostos pelo trabalho, ao mapear as bases teóricas do design emocional, constatou-se que na literatura existem inúmeras teorias que cercam o campo do design e da emoção, todavia, não foi verificado um consenso entre elas e nem como esses estudos possam corroborar para o desenvolvimento de produtos no campo de design e emoção. Fato esse também identificado através das análises das metodologias de design existentes, especialmente as que contemplam os aspectos emocionais, uma vez que se verificou não haver uma metodologia específica para o desenvolvimento de produtos "emocionais". O que encontramos foram modelos e ferramentas que têm o intuito de entender e verificar o grau e o tipo de emoção despertada a partir da interação dos usuários com os produtos.

Durante a pesquisa, identificou-se também a existência de modelos de compreensão de como esse procedimento é desenvolvido e quais os tipos de influências que podem interferir/direcionar neste processo. Desta forma, foi gerado 
um modelo de análise do design emocional, que foi construído a partir dos referenciais teóricos desta pesquisa e das análises dos métodos, ferramentas e modelos de design. Este modelo, que será apresentado mais adiante, foi desenvolvido através do método de Mapas de Associação de Ideias, explicado na metodologia, resultando na seguinte figura resumo:

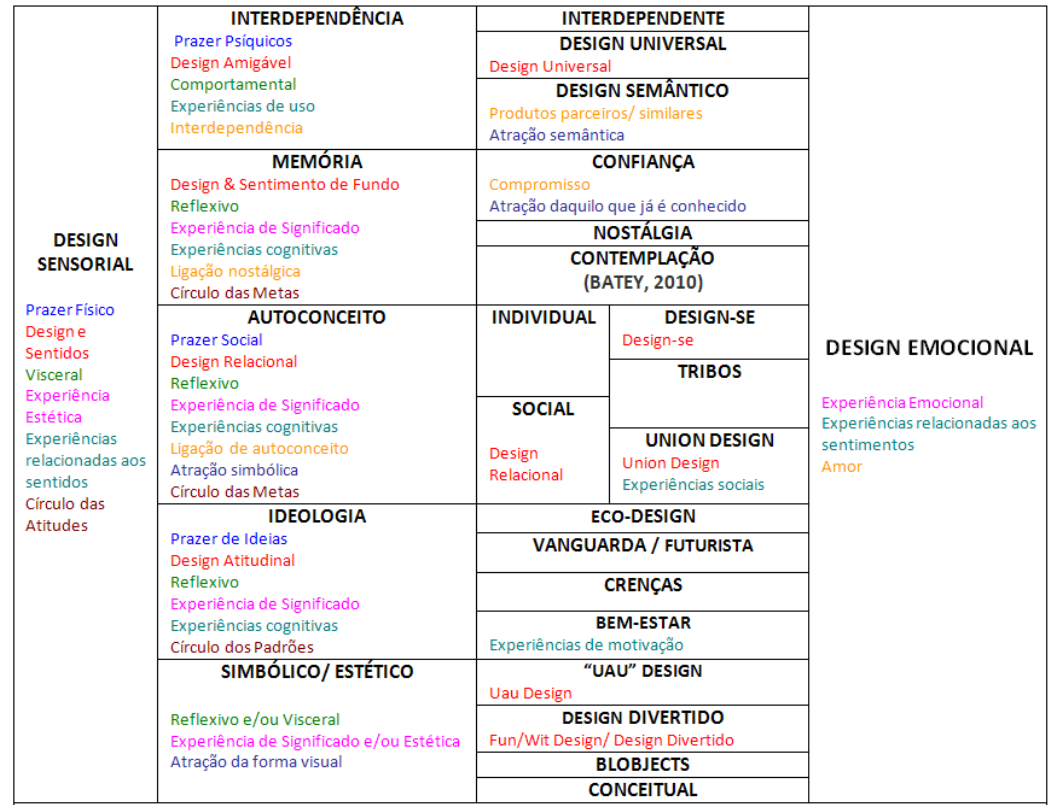

Figura 6 - Síntese: Mapa de Associações de Ideias.

Fonte: Elaborado pelo autor, inspirado em Baxter (2003); Batey (2010); Ceccon e Damazio (2010); Desmet e Hekkert (2007); Jordan (2002); Norman (2008); Ribeiro (2006); Solomon (2008) e Fournier (1998); Scolari (2008).

Desta forma, elaborou-se o MADE, Modelo de Análise do Design Emocional, com o intuito de entender melhor e classificar o tipo de envolvimento que um objeto pode ter com o usuário.

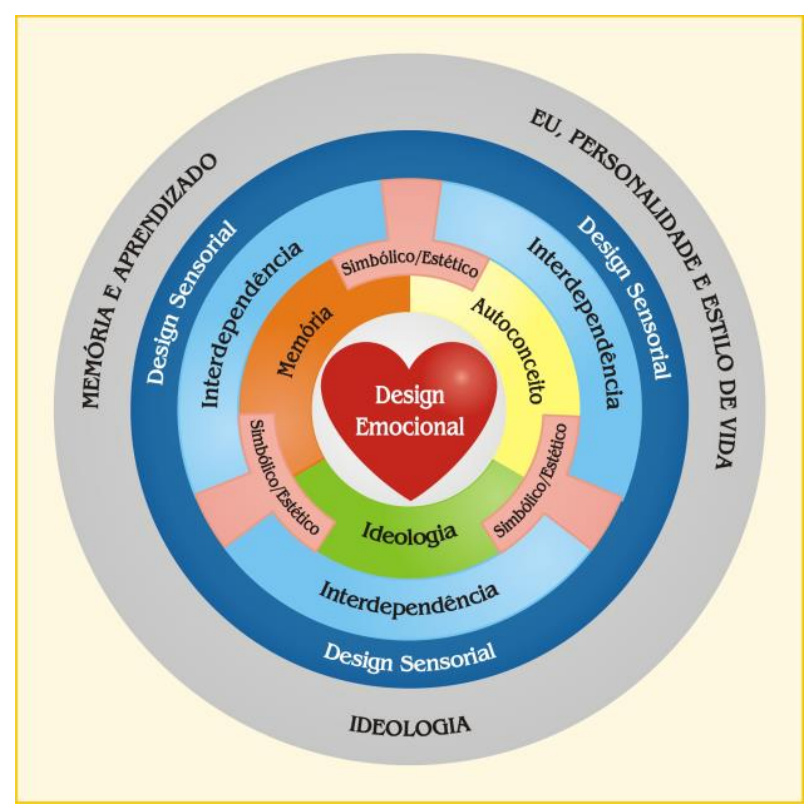

Figura 7 - MADE: Modelo de Análise do Design Emocional.

Fonte: Elaborado pelo autor, com base na pesquisa realizada. 
Esse modelo, construído através da técnica de mapas de ideas, foi desenvolvido a partir da união das teorias e de modelos que circunscrevem o campo do design e emoção. Nele, podemos observar o grau de envolvimento do usuário com o produto, onde quanto mais próximo ao centro, maior é o seu envolvimento. Além disso, podemos perceber qual o tipo de relação que o MADE pode ter com esses objetos, sendo definidas sete classificações principais:

Design Sensorial: primeiro nível de contato entre usuário e produto. Ocorre através do sistema sensorial;

Design de Interdependência: refere-se aos produtos que cumprem sua função de uso, isto é, sua função prática. Subclasses: Interdependente, Universal, Semântico;

Design de Memória: refere-se aos produtos que já estabelecem vínculos de lembranças de uso e aprendizado com os usuários. Subclasses: Confiança, Nostalgia, Contemplação;

Design de Autoconceito: trata-se dos produtos que ajudam a estabelecer uma identidade para o usuário, podendo ser individual ou social. Subclasses: Individual (Design-se, Tribos), Design Social (Union Design, Tribos);

Design de Ideologia: refere-se aos produtos que compartilham uma ideologia de vida, isto é, uma forma de pensar em prol de uma causa de pessoal, social, ambiental, futurista, etc. Subclasses: Bem-Estar; Crenças/Valores, Vanguarda/ Futurista, Eco-Design;

Design Simbólico/Estético: trata-se dos produtos que possuem um apelo simbólico e/ou estético muito marcante, podendo está no nível de interdependente ou não, bem como fazer parte concomitantemente aos outros níveis já relacionados. Subclasses: Blobjects, Conceitual, Divertido, "Uau” Design;

Design Emocional: nível mais intenso de sentimentos despertados pelos objetos. Contempla todas as experiências de uso e interação do usuário com os seus objetos.

É importante ressaltar que essas classificações compartilham características em comuns, ou seja, um objeto pode apresentar vários níveis ao mesmo tempo. Além disso, é possível a inserção de mais subclasses para os níveis descritos acima.

Através do mapeamento apresentado sobre o design emocional e sua relação com os usuários, idealizou-se um Modelo de Análise do Design Emocional, o MADE (Figura 7).

Ao mapear artefatos de design que tiveram destaque em revistas da área sob uma perspectiva emocional, contatou-se que de acordo com a busca em revistas especializadas, o número de objetos desenvolvidos por especialistas em design voltados para a população de massa é extremante pequeno se comparado aos outros objetos de design referenciados nestas publicações. Como resultado, foram selecionados cinco produtos que mais se adequavam aos critérios estabelecidos na pesquisa, sendo: a Garrafa Térmica Aladdin Futura; a Lixeira Romeu e Julieta; as Sandálias Melissas Zig Zag; o Conjunto de Mesa Native e o Prendedor Multifuncional.

A análise desses produtos no focus group revelou que, os especialistas que já conheciam esses artefatos, tinham reações emocionais mais profundas do que aqueles que não eram usuários. Estes últimos analisavam os produtos de forma mais técnica e imparcial em relação às emoções. Por outro lado, não se verificou um consenso em quais tipos de emoções poderiam ser despertadas na maioria dos produtos analisados, o que demonstra uma dificuldade de se projetar um objeto sem ter como base um modelo de referência. 
Outro fator que chamou a atenção foi o fato de que apenas três destes cinco objetos estarem no mercado e apenas dois preservarem nos dias atuais suas características principais, sendo as Melissas projetadas pelos Irmãos Campanas e as lixeiras Romeu e Julieta fabricadas pela Coza. A Garrafa Térmica Aladdin Futura foi redesenhada, sendo acrescentando um sistema de pega ao seu corpo. Já o Prendedor Multiuso e a Mesa Native, ambas da Coza, saíram da linha de fabricação. Deste modo, fica aqui uma indagação: como pode objetos premiados e reconhecidos por instituições de design não serem sucesso de vendas ou terem que se adaptar ao mercado para vender, como no caso da Garrafa Térmica Aladdin Futura?

Uma possível explicação para esta pergunta estaria na base do design emocional. Por exemplo, a forma inovadora do Prendedor Multiuso e da Garrafa Térmica Aladdin Futura, sem pega, romperia com os padrões já conhecidos pelos seus usuários que, por sua vez, não se sentem seguros em utilizar esses produtos. Se pegarmos ainda o caso da Garrafa Futura, vemos que após a inserção da pega, ela se tornou campeã em vendas. Deste modo, podemos perceber que uma simples alça, em uma garrafa, faz parte da interdependência e da memória de muitos usuários que sem esta, ficam inseguros em utilizá-las.

Em relação às respostas obtidas com os usuários das sandálias Melissas Campana, pode-se evidenciar através do MADE, o grau e o tipo de envolvimento que um produto pode ter com seus usuários. Nesta análise, observou-se a presença de sensações positivas logo no primeiro nível, que diz respeito ao Design Sensorial. Também se observou a presença do Nível de Interdependência, responsável pela função de uso do produto, nas afirmações das entrevistadas, em que tivemos dez sensações positivas e uma negativa.

Quanto ao nível do Design de Memória, responsável por estabelecer vínculos de lembranças, percebeu-se, nos depoimentos das entrevistadas, a presença do Design de Nostalgia e de Contemplação. No Design de Autoconceito, constatou-se a presença do Design de Tribos, tanto o aspecto Individual, quanto o Social. Todavia, não foi encontrada referência direta ao nível do Design Emocional, porém observa-se que mesmo sem esta, esse nível faz parte de muitas das entrevistadas, uma vez que esse nível está relacionado a todas as experiências de uso e interação do usuário com os seus objetos, como podemos perceber no seguinte depoimento "Bom as sandálias passaram a possuir valor afetivo e me trazem boas lembranças, mas isso é muito mais devido às situações que vivi com elas nos pés do que por serem dos Campana. Aline "Doce" P. (23 anos)".

Por fim, a utilização do MADE como ferramenta, pode auxiliar no trabalho tanto de pesquisas relacionadas à emoção quanto no desenvolvimento de produtos com foco na emoção. Por exemplo, aplica-se o MADE a um produto similar ou aos produtos que fazem parte do entorno deste usuário, verificando-se o nível e o grau de envolvimento entre estes consumidores. Após a compreensão desta relação, tenta-se atribuir através dos elementos de configuração do design, características relevantes encontradas através do MADE, como sugere Denton e Mcdonagh (2006).

Alguns produtos parecem gerar fortes reações emocionais entre grupos de usuários específicos, sendo frases como "o amo" e "o odeio" muitas vezes dita e ouvida. Como os projetos estão deixando cada vez mais de se voltar apenas para o produto em si e está mais centrado nas experiências dos usuários, torna-se cada vez mais importante que os designers estejam sensíveis e conscientes das experiências dos usuários. Desenvolver a empatia está provando ser um elemento valioso no apoio à concepção resultados mais eficazes (DENTON e MCDONAGH, 2006). 
Com o objetivo de confrontar os dados levantados pelos especialistas, realizouse uma pesquisa envolvendo os usuários e um dos produtos estudados. Dentre os produtos analisados, atualmente apenas dois destes objetos preservam suas características originais, as Melissas projetadas pelos Irmãos Campanas e as lixeiras Romeu e Julieta fabricadas pela Coza. A Garrafa Térmica Aladdin Futura foi redesenhada, sendo acrescentado um sistema de pega ao seu corpo. Já o Prendedor Multiuso e a Mesa Native, ambas da Coza, saíram da linha de fabricação. Desta forma, optou-se pelas sandálias Melissas, uma vez que dentre os produtos estudados, elas são facilmente encontradas no mercado, sendo possível uma maior interação com seus usuários.

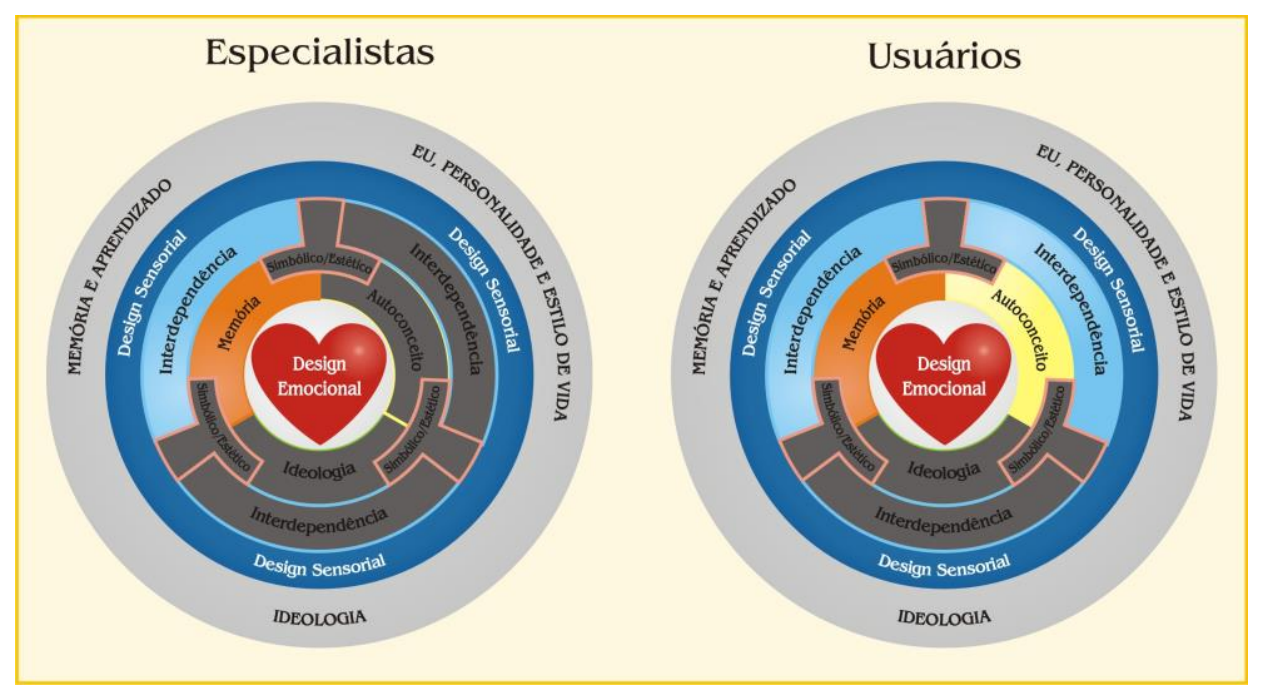

Figura 8 - Simulação MADE - Comparação entre Especialistas e Usuários.

Fonte: Elaborado pelo autor, com base na pesquisa realizada.

Quando comparamos as respostas dos especialistas e dos usuários (Figura 8) sobre este produto, percebemos que é possível antecipar algumas sensações positivas e afetivas nos usuários. Um exemplo neste produto é a recordação de infância, atribuída a essência de tutti-frutti no produto. A sensação e o prazer físico também pode ser antecipado pelos especialistas através das características deste produto. Logo, verifica-se que é possível através dos elementos de configuração do design, antecipar possíveis vínculos afetivos que o produto possa vir a ter com seus usuários por meio do sistema sensorial humano.

\section{CONCLUSÃO}

Diante do exposto, conclui-se que é possível evidenciar e analisar a relação existente no desenvolvimento de artefatos de design e os aspectos emocionais despertados nos usuários através da sua relação com estes objetos, mesmo que sejam difíceis prever, inicialmente, qual o tipo e o grau de envolvimento que estes possam vir a estabelecer com estes produtos. Para trabalhos futuros, sugiro: investigar a sensação e a percepção dos usuários através do sistema sensorial humano a fim de ampliar o campo do design e emoção; desenvolver metodologias de design e emoção a partir da percepção dos sistemas sensoriais; aperfeiçoar e aprofundar as subcategorias do MADE de acordo do as teorias do design emocional; explorar o MADE como ferramenta inspiradora para a criação de métodos de criação do design. 


\section{REFERÊNCIAS}

BATEY, Mark. O significado da marca: como as marcas ganham vida na mente dos consumidores. Rio de Janeiro: Best Business, 2010.

BAXTER, M. Projeto do produto: guia prático para o desenvolvimento de novos produtos. São Paulo: Edgard Blücher, 2003.

CECCON, Marília. DAMAZIO. Vera. Design Emocional: contribuindo para uma nova forma de projetar. Pdf. Disponível na internet por http em: <http://www.puc-rio.br/ pibic/relatorio resumo2009/resumos/art/marilia.pdf >. Acesso em 20 de jan de 2011.

DAMÁSIO, Antônio. A força da inteligência na sua vida. Veja, ano 34, n. 25, p. 92-99, 2001.

DAMÁSIO, Antônio. O Mistério da Consciência. São Paulo: Companhia das Letras, 2006.

DAMAZIO, Vera. LIMA, Júlia. MEYER, Guilherme. "Marcas que marcam" e Antropologia do Consumo: caminhos para projetar produtos "marcantes". In: MONT'ALVÃO, Claudia; DAMAZIO, Vera (orgs.). Design, ergonomia e emoção. Rio de. Janeiro, Mauad X:FAPERJ, 2008. p. 65-86.

DESMET, P. M. A.; HEKKERT, P. Framework of product experience. In: International Journal of Design, 2007, p. 57-66.

FAGGIANI, Kátia. O Poder do Design: da ostentação à emoção. Brasília, DF: Thesaurus, 2006.

FOURNIER, Susan. Consumers and their brands: developing relationship theory in consumer research. In: Journal od Consumer Research 24, March 1998. p 343-373.

IIDA, Itiro. Design Emocional: conexão emocional entre produto e consumidor. 6으 congresso brasileiro de gestão de desenvolvimento de produto. Belo Horizonte, 2007. Ppt. Disponível na internet por http em: <webmail.faac.unesp.br/ paula/Paula/ palestra design emocional.ppt>. Acesso em set de 2008.

JORDAN, Patrick W. How to make brilliant stuff that people love. West Sussex: John Wiley \& Sons Inc., 2002

LÖBACH, Bernd. Design Industrial, São Paulo: Blücher, 2000.

NORMAN, Donald A. Design Emocional: por que adoramos (ou detestamos) os objetos do dia-a-dia. Rio de Janeiro: Rocco, 2008.

RIBEIRO, Marcos Buccini Pio. Design Experencial em Ambientes Digitais: um estudo do uso de experiências em web sites e junto a designers e usuários de Internet. 2006. 144p. Dissertação (mestrado) - Universidade Federal de Pernambuco, Programa de Pós-Graduação em Design.

ROESCH, Sylvia Maria Azevedo. Projetos de estágio e pesquisa em administração: guia para estágios, trabalhos de conclusão, dissertações e estudos de caso. Colaboração Grace Vieira Becker, Maria Ivone de Mello. 3. ed. São Paulo: Atlas, 2007.

SCOLARI, Sérgio Henrique P. Design e Emoção: um modelo de círculos de referencias de emoção em produtos. 2008. 64p. Dissertação (mestrado) - Universidade Estadual Paulista, Programa de Pós-Graduação em Design.

SOLOMON, Michaer R. O Comportamento do Consumidor: comprando, possuindo e sendo. Porto Alegre: Bookman, 2008.

VERGARA, Sylvia Constant. Projetos e relatórios de pesquisa em administração. 9. ed. São Paulo: Atlas, 2007. 